\title{
PENGARUH PENAMBAHAN GULA JAGUNG TERHADAP SIFAT MEKANIK DAN BIODEGRADABILITAS PLASTIK CAMPURAN POLYPROPYLENE BEKAS DAN PATI SAGU
}

\author{
Sri Mulyadi Dt Basa, Afdhal Muttaqin, Maria Elvi Hutagalung \\ Jurusan Fisika Universitas Andalas - Padang \\ srimulyadi@fmipa.unand.ac.id
}

\begin{abstract}
ABSTRAK
Penelitian ini dilakukan untuk menentukan pengaruh gula jagung terhadap sifat mekanik dan biodegradabilitas plastik campuran polypropylene bekas dan pati sagu. Pada penelitian ini dibuat 5 sampel dengan variasi massa gula jagung yang berbeda. Pengukuran dilakukan terhadap kuat tekan dan kuat lentur dari setiap sampel. Penentuntuan tingkat degradabilitas ditentukan dengan mengubur sampel selama tujuh hari. Hasil menunjukkan bahwa kuat lentur dan kuat tekan plastik mengalami kenaikan dengan penambahan gula jagung. Nilai kuat tekan dan kuat lentur maksimum terdapat pada komposisi 90 gr : 10 gr : 10 gr yaitu $87,04 \mathrm{~kg} / \mathrm{cm}^{2}$ dan $96,9 \mathrm{~kg} / \mathrm{cm}^{2}$. Ditinjau dari segi fisis setelah proses penguburan, plastik campuran dengan komposisi gula jagung terbanyak memiliki permukaan paling kasar dan paling banyak lobang. Hal ini dapat diartikan bahwa plastik dengan komposisi gula jagung terbanyak memiliki tingkat degradabilitas tertinggi.
\end{abstract}

Kata kunci : Kuat lentur, kuat tekan, biodegradabilitas, polypropylene, pati sagu dan gula jagung.

\section{PENDAHULUAN}

Penggunaan plastik dewasa ini terus mengalami peningkatan seiring dengan pertambahan populasi penduduk. Hal ini dikarenakan oleh banyaknya keunggulan plastik dibandingkan bahan lain. Namun di sisi lain, penggunaan plastik ternyata mendatangkan berbagai persoalan lingkungan. Penumpukan sampah plastik menjadi persoalan yang dihadapi setiap daerah yang semakin memburuk setiap waktunya. Penumpukan ini terjadi karena sampah plastik tidak dapat diuraikan secara alami oleh mikroba di dalam tanah dalam waktu yang singkat.

Permasalahan sampah plastik ternyata tidak menyurutkan animo masyarakat dalam intensitas penggunaan plastik. Ketergantungan manusia pada plastik memang tidak dapat digantikan sama sekali. Walaupun di beberapa negara telah mengeluarkan kebijakan untuk mengurangi penggunaan plastik, namun tidak serta merta menjawab akibat yang ditimbulkan oleh menumpuknya sampah plastik.

Penumpukkan sampah plastik terjadi karena penguraian yang memakan waktu lama. Penguraian yang lama ini diakibatkan karena material plastik sulit diuraikan oleh mikroba di dalam tanah secara alami. Peningkatan kinerja mikroba dapat dilakukan dengan menambahkan bahan organik yang dapat diuraikan oleh mikroorganisme secara cepat sehingga menjadi plastik yang ramah lingkungan. Jenis plastik ini lebih dikenal dengan plastik biodegradable (Budiman, 2003, Fahruddin, dkk, 2010, Flieger dkk, 2003).

Salah satu jenis plastik yang banyak digunakan adalah dari jenis polypropylene (Emriadi, 2005, Billmayer, 1971). Untuk dapat dijadikan sebagai plastik biodegradable, pada polypropylene perlu ditambahkan bahan organik homopolimer glukosa seperti pati sagu (Fahruddin dkk, 2010, Firdaus dkk, 2004, Flieger dkk, 2003, Pranamuda, 2009). Untuk mempertahankan sifat mekaniknya, dapat ditambahkan gula jagung sebagai bahan pemlastis. Gula jagung (sorbitol) merupakan pemlastis yang efektif karena memiliki 
kemampuan untuk mengurangi ikatan hidrogen internal pada ikatan intermolekul (Harahap, 2009).

\section{METODE PENELITIAN}

Bahan yang digunakan pada penelitian ini adalah plastik kemasan polypropylene bekas, pati sagu dan gula jagung. Adapun variasi massa gula jagung adalah 0 gr, 2 gr, 4 gr, 8 gr dan 10 gr, pati sagu 10 gr serta plastik kemasan polypropylene sebanyak 90 gr. Selanjutnya dilakukan pengujian sifat mekanik (kuat tekan dan kuat lentur), dan uji degradabilitas. Pengujian mekanik menggunakan mesin kompresor, dengan ukuran sampel $5 \mathrm{~cm}$ x $5 \mathrm{~cm}$ x $5 \mathrm{~cm}$ untuk sampel uji tekan dan $15 \mathrm{~cm} \times 3 \mathrm{~cm} \times 2 \mathrm{~cm}$ untuk sampel uji lentur. Untuk mengetahui tingkat degradabilitas, sampel akan dikubur selama 7 hari di dalam tanah berlumpur.

\section{HASIL DAN PEMBAHASAN Hasil Pengujian Kuat Lentur ( $f r$ )}

Pada Tabel 1 dan Tabel 2 dapat dilihat bahwa nilai kuat lentur semakin meningkat dengan bertambahnya jumlah gula jagung. Semakin banyak gula jagung yang ditambahkan, maka semakin besar nilai kuat lenturnya. Hal ini dapat dilihat dengan jelas pada Gambar 2, dimana kuat lentur meningkat dengan meningkatnya jumlah gula jagung. Dapat dikatakan bahwa gula jagung merupakan pemlastis yang baik bagi plastik campuran polypropylene dan pati sagu. Hal ini dapat terjadi karena gula jagung dapat larut dalam tiap-tiap rantai polimer polypropylene dan pati sagu. Proses ini diilustrasikan seperti pada Gambar 3.

Tabel 1 Nilai kuat lentur masing-masing sampel sebelum penguburan

\begin{tabular}{|c|c|c|c|c|c|}
\hline \multirow{2}{*}{ Sampel } & \multicolumn{5}{|c|}{ Kuat Lentur $\left(\mathrm{kg} / \mathrm{cm}^{2}\right)$} \\
\cline { 2 - 6 } & $(90: 10: 0)^{*}$ & $(90: 10: 2)^{*}$ & $(90: 10: 4)^{*}$ & $(90: 10: 8)^{*}$ & $(90: 10: 10)^{*}$ \\
\hline 1 & 30,6 & 45,9 & 61,2 & 91,8 & 91,8 \\
\hline 2 & 45,9 & 53,55 & 68,85 & 91,8 & 107,1 \\
\hline 3 & 53,55 & 45,9 & 76,5 & 84,15 & 91,8 \\
\hline Rata-rata & 43,35 & 48,45 & 68,85 & 89,25 & 96,9 \\
\hline
\end{tabular}

*perbandingan polypropylene: pati sagu: gula jagung dalam gram

Tabel 2 Nilai kuat lentur masing-masing sampel sesudah penguburan

\begin{tabular}{|c|c|c|c|c|c|}
\hline \multirow{2}{*}{ Sampel } & \multicolumn{5}{|c|}{ Kuat Lentur $\left(\mathrm{kg} / \mathrm{cm}^{2}\right)$} \\
\cline { 2 - 6 } & $(90: 10: 0)^{*}$ & $(90: 10: 2)^{*}$ & $(90: 10: 4)^{*}$ & $(90: 10: 8)^{*}$ & $(90: 10: 10)^{*}$ \\
\hline 1 & 30,6 & 30,6 & 61,2 & 76,5 & 91,8 \\
\hline 2 & 45,9 & 45,9 & 45,9 & 76,5 & 84,15 \\
\hline 3 & 45,9 & 61,2 & 61,2 & 76,5 & 84,15 \\
\hline Rata-rata & 40,8 & 45,9 & 56,1 & 76,5 & 86,7 \\
\hline
\end{tabular}

*perbandingan polypropylene: pati sagu: gula jagung dalam gram 


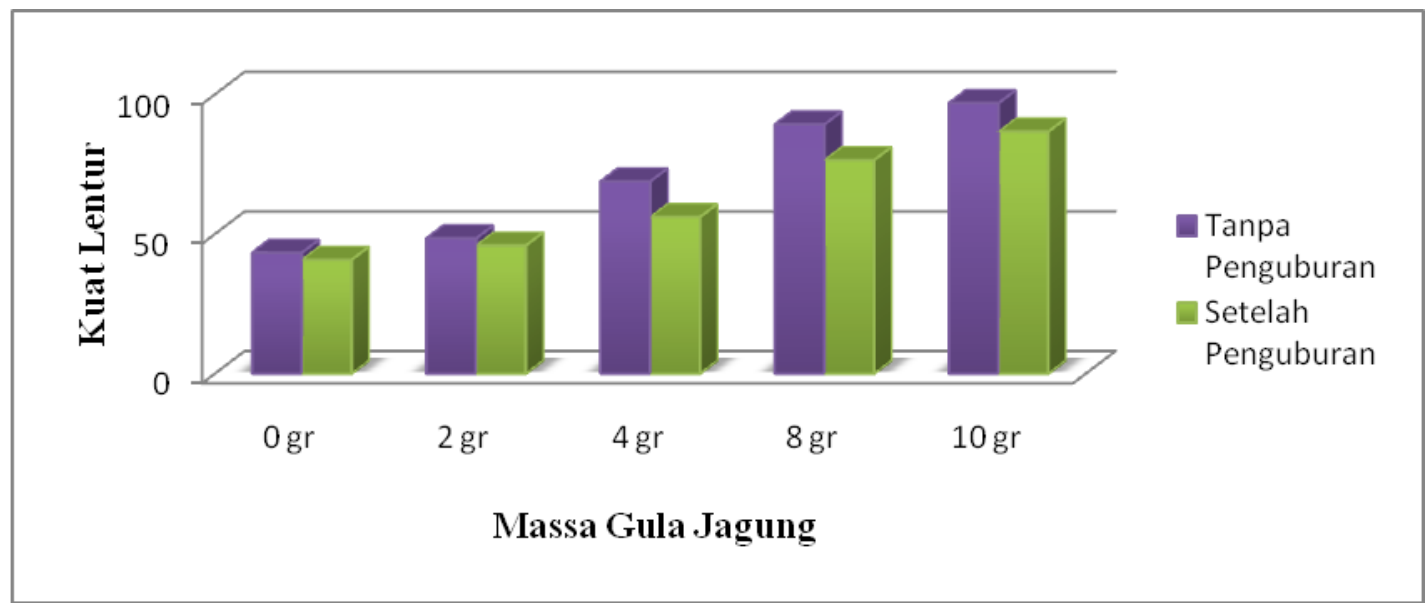

Gambar 2 Diagram perbandingan nilai kuat lentur sampel pada masing-masing konsentrasi gula jagung sebelum dan sesudah penguburan

(a)

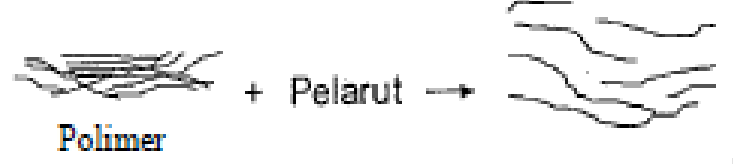

(b)

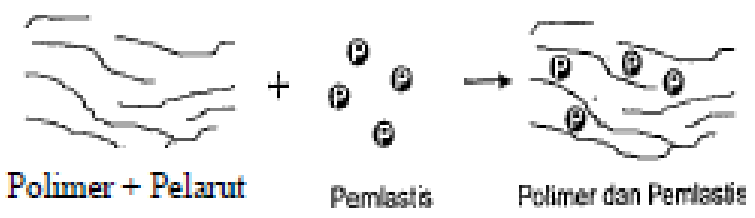

Gambar 3 (a) Reaksi antara polimer dan pelarut (b) Reaksi penambahan pemlastis pada polimer (Spink dan Waychoff, 1958)

\section{Hasil Pengujian Kuat Tekan $\left(\sigma_{l}\right)$}

Berdasarkan Tabel 3 dan Tabel 4, nilai kuat tekan meningkat dengan bertambahnya jumlah gula jagung. Semakin banyak gula jagung yang ditambahkan, maka semakin tinggi kuat tekannya. Kuat tekan minimum terjadi pada plastik campuran polypropylene pati sagu tanpa gula jagung yaitu $54,4 \mathrm{~kg} / \mathrm{cm}^{2}$ sedangkan kuat tekan maksimum 87,04 $\mathrm{kg} / \mathrm{cm}^{2}$ terjadi pada penambahan gula jagung sebanyak 10 gr. Hal ini dapat dilihat jelas pada Gambar 4, dimana grafik semakin tinggi dengan bertambahnya jumlah gula jagung.

Tabel 3 Nilai kuat tekan masing-masing sampel sebelum penguburan

\begin{tabular}{|c|c|c|c|c|c|}
\hline \multirow{2}{*}{ Sampel } & \multicolumn{5}{|c|}{ Kuat Tekan $\left(\mathrm{kg} / \mathrm{cm}^{2}\right)$} \\
\cline { 2 - 6 } & $(90: 10: 0)^{*}$ & $(90: 10: 2)^{*}$ & $(90: 10: 4)^{*}$ & $(90: 10: 8)^{*}$ & $(90: 10: 10)^{*}$ \\
\hline 1 & 48,96 & 61,2 & 69,36 & 89,76 & 81,6 \\
\hline 2 & 61,2 & 61,2 & 53,04 & 81,6 & 77,52 \\
\hline 3 & 57,12 & 53,04 & 81,6 & 69,36 & 102 \\
\hline Rata-rata & 55,76 & 58,48 & 68 & 80,24 & 87,04 \\
\hline
\end{tabular}

*perbandingan polypropylene: pati sagu: gula jagung dalam gram 
ISSN 1979-4657

Tabel 4 Nilai kuat tekan masing-masing sampel sesudah penguburan

\begin{tabular}{|c|c|c|c|c|c|}
\hline \multirow{2}{*}{ Sampel } & \multicolumn{5}{|c|}{ Kuat Tekan $\left(\mathrm{kg} / \mathrm{cm}^{2}\right)$} \\
\cline { 2 - 6 } & $(90: 10: 0)^{*}$ & $(90: 10: 2)^{*}$ & $(90: 10: 4)^{*}$ & $(90: 10: 8)^{*}$ & $(90: 10: 10)^{*}$ \\
\hline 1 & 65,28 & 57,12 & 81,6 & 81,6 & 81,6 \\
\hline 2 & 57,12 & 57,12 & 61,2 & 81,6 & 73,44 \\
\hline 3 & 40,8 & 57,12 & 57,12 & 65,28 & 89,76 \\
\hline Rata-rata & 54,4 & 57,12 & 66,64 & 76,12 & 81,6 \\
\hline
\end{tabular}

*perbandingan polypropylene: pati sagu: gula jagung dalam gram

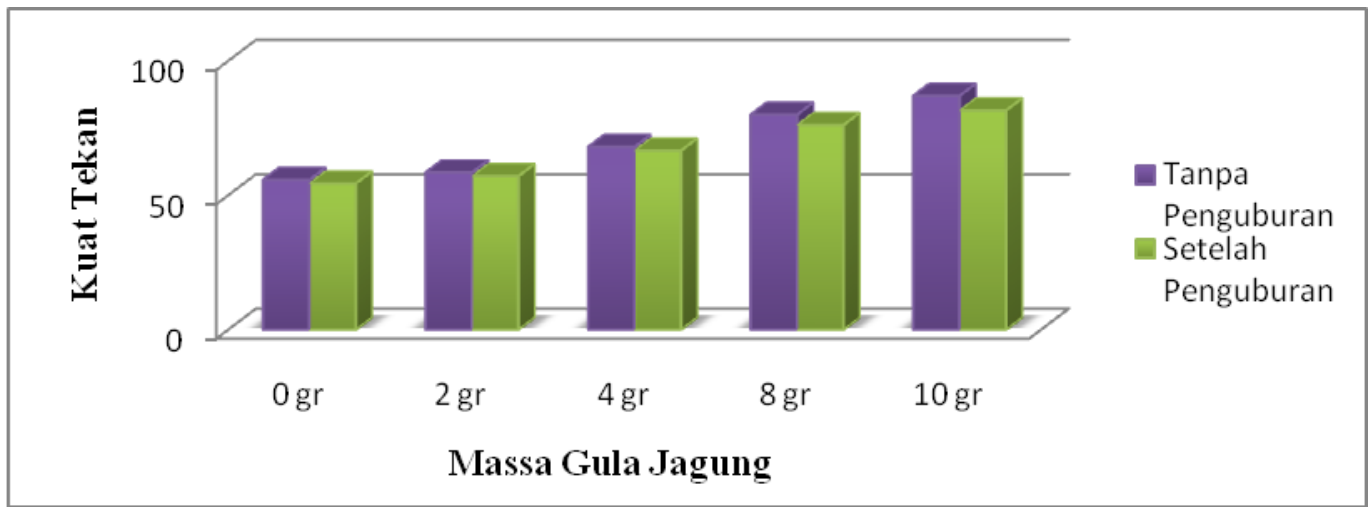

Gambar 4 Diagram perbandingan nilai kuat tekan sampel pada masing-masing konsentrasi gula jagung sebelum dan sesudah penguburan

Peningkatan kuat tekan dengan penambahan gula jagung disebabkan oleh kemampuan molekul gula jagung dalam mengurangi ikatan hidrogen internal pada ikatan intermolekul, sehingga dapat menurunkan suhu Tg. Hal ini dapat mengurangi kerapuhan dan meningkatkan fleksibilitas (Harahap, 2009).

Tabel 5 Perbandingan permukaan sampel uji kuat lentur

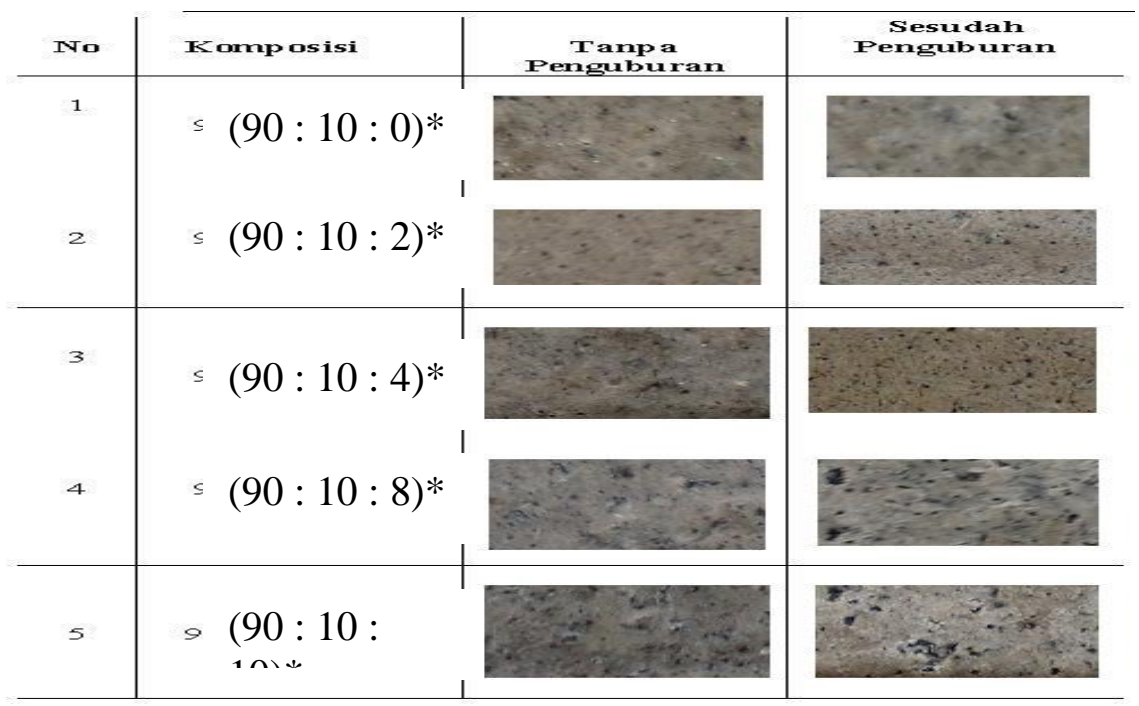

*perbandingan polypropylene: pati sagu: gula jagung dalam gram 


\section{Hasil Uji Degradabilitas}

Untuk mengetahui tingkat degradabilitas masing-masing sampel, dapat dilihat pada Tabel 6. Dari Tabel 6, dapat dilihat bahwa terdapat perbedaan kekasaran permukaan dari masing-masing sampel. Semakin banyak gula jagung yang ditambahkan, semakin kasar permukaannya. Pada kolom setelah penguburan, dapat dilihat bahwa kekasaran permukaan meningkat dengan penambahan massa gula jagung. Permukaan yang paling kasar dan berlobang terdapat pada kolom dan baris terakhir pada komposisi 90gr:10gr:10gr. Hal ini dapat terjadi karena bertambahnya material organik pada plastik campuran tersebut, sehingga memudahkan mikroorganisme dalam proses penguraian (Firdaus, 2004).

\section{KESIMPULAN}

Dari data yang diperoleh nilai mekanik terbaik dimiliki oleh sampel yang mengandung 10 gr gula jagung dengan nilai kuat lentur $96,9 \mathrm{~kg} / \mathrm{cm}^{2}$ dan nilai kuat tekan 87,04 $\mathrm{kg} / \mathrm{cm}^{2}$. Jika ditinjau dari segi fisis, plastik campuran polypropylene pati sagu dan gula jagung merupakan plastik biodegradable karena permukaan plastik dapat terurai oleh mikroorganisme tanah dalam waktu 7 hari. Campuran plastik polypropylene pati sagu dengan kandungan 10 gr gula jagung merupakan plastik yang dapat terurai dengan cepat dengan sifat mekanik yang baik

\section{DAFTAR PUSTAKA}

1. Billmayer, F.W. Jr, 1971, Text Book of Polymer Science, John Wiley and Sons, New York.

2. Budiman N., 2003, Polimer Biodegradable, http://www.kompas.com/ 0302/28/ llpeng/151875.htm-35k.

3. Emriadi, 2005, Material Polimer, Andalas University Press, Padang.

4. Fahruddin, Sonai dan Indah, 2010, Pembuatan Plastik Biodegradable Berbasis Ubi Kayu Dengan Aditif Senyawa Limonen Dari Kulit Jeruk Untuk Meningkatkan Elastisitas, Program Kreativitas Mahasiswa Jurusan Kimia FMIPA Universitas Negeri Malang, Malang.

5. Firdaus, F. dan Anwar, C., Juli 2004, Potensi Limbah Padat-cair Industri Tepung Tapioka sebagai Bahan Baku Film Plastik Biodegradabel, LOGIKA, Vol. 1, No. 2, Hal 38-44, Yogyakarta.

6. Flieger MM, Kantorova A, Prell T, 2003, Biodegradable Plastic From Renewable Sources, J Folia Microbiol 48910:22-44.

7. Harahap, A.P, 2009, Pelapisan Melon Menggunakan Film Edibel dari Pati Ubi Kayu dengan Penambahan Sorbitol sebagai Zat Pemlastis, skripsi Departemen Teknologi Pertanian Fakultas Pertanian Universitas Sumatera Utara, Medan.

8. Pranamuda, H, 2009, Pengembangan Bahan Plastik Biodegradabel Berbahan Baku Pati Tropis, Badan Pengkajian dan Penerapan Teknologi Jakarta. Weblog Biology Resources on Shantybio.

9. Spink, W. P dan W.F. Waychoff 1958/1959 Plasticizers, Frados, Joel (ed.), Modern Plastic Encyclopedia Issue. Hildrent Press, Inc. New York. 